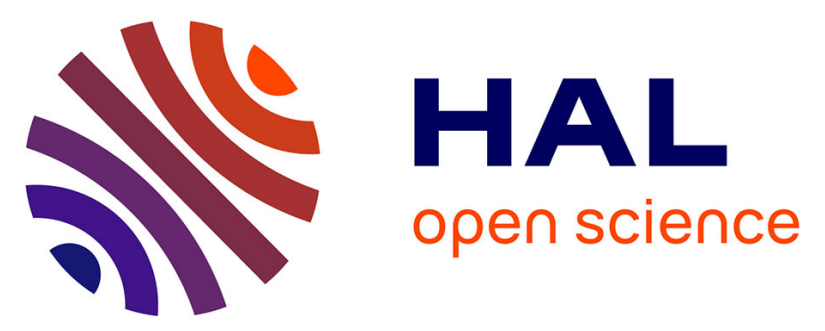

\title{
Discoloration of simulated textile effluent in continuous photoreactor using immobilized titanium dioxide: Effect of zinc and sodium chloride
}

\author{
Ahmed Amine Azzaz, Aymen Amine Assadi, Salah Jellali, Abdelkarim \\ Bouzaza, Dominique Wolbert, Sami Rtimi, Latifa Bousselmi
}

\section{To cite this version:}

Ahmed Amine Azzaz, Aymen Amine Assadi, Salah Jellali, Abdelkarim Bouzaza, Dominique Wolbert, et al.. Discoloration of simulated textile effluent in continuous photoreactor using immobilized titanium dioxide: Effect of zinc and sodium chloride. Journal of Photochemistry and Photobiology A: Chemistry, 2018, 358, pp.111-120. 10.1016/j.jphotochem.2018.01.032 . hal-01774415

HAL Id: hal-01774415

https://hal-univ-rennes1.archives-ouvertes.fr/hal-01774415

Submitted on 27 Apr 2018

HAL is a multi-disciplinary open access archive for the deposit and dissemination of scientific research documents, whether they are published or not. The documents may come from teaching and research institutions in France or abroad, or from public or private research centers.
L'archive ouverte pluridisciplinaire HAL, est destinée au dépôt et à la diffusion de documents scientifiques de niveau recherche, publiés ou non, émanant des établissements d'enseignement et de recherche français ou étrangers, des laboratoires publics ou privés. 


\title{
Discoloration of simulated textile effluent in continuous photoreactor using immobilized titanium dioxide: effect of zinc and sodium chloride
}

\author{
Ahmed Amine AZZAZ ${ }^{1,2,3}$, Aymen Amine ASSADI ${ }^{3, \star}$, Salah JELLALI ${ }^{1}$, Abdelkarim \\ BOUZAZA $^{3}$, Dominique WOLBERT ${ }^{3}$, Sami RTIMI ${ }^{4}$, Latifa BOUSSELMI ${ }^{1}$ \\ ': Wastewaters and Environment Laboratory, Water Research and Technologies Center, BP 273, Soliman 8020, \\ Tunisia \\ ${ }^{2}$ : University of Carthage, Faculty of Sciences of Bizerte, Jarzouna 7000, Tunisia \\ 3: Équipe Chimie et Ingénierie des Procédés, UMR 6226 CNRS, ENSCR-11, allée de Beaulieu, CS 508307- \\ 35708 Rennes, France \\ ${ }^{4}$ École Polytechnique Fédérale de Lausanne, EPFL-STI-LTP, Station 12, CH-1015 Lausanne, Switzerland.
}

\begin{abstract}
In the present research, the optimization of the photocatalytic degradation of simulated textile effluent containing two pollutants (Methylene blue (MB) and Zinc) consisted of studying the variation of four parameters, namely initial $\mathrm{MB}$ concentration $\left([\mathrm{MB}]_{\mathrm{I}}, \mathrm{mg} / \mathrm{L}\right)$, zinc concentration $\left(\left[\mathrm{Zn}^{2+}\right]_{\mathrm{I}}, \mathrm{mg} / \mathrm{L}\right)$, sodium chloride concentration $\left([\mathrm{NaCl}]_{\mathrm{I}}, \mathrm{M}\right)$ and flow rate (Q, mL/min) through a design of experiment using the response surface methodology approach. Results showed that MB degradation depends by order of importance on $\mathrm{NaCl}$ concentration > MB concentration > ionic zinc concentration > flowrate. Modeling results presented a good concordance between predicted and experimental values with acceptable correlation coefficients $\left(\mathrm{R}^{2}=0.9879\right.$ and $\mathrm{R}^{2}$ (adjusted) $\left.=0.9773\right)$. Desirability function was applied on the second-order polynomial equation to determine the optimal experimental condition for fastest total photocatalytic degradation and it was identified as follows: For a
\end{abstract}

\footnotetext{
* Corresponding author: 11, Allée de Beaulieu, CS 508307-35708 Rennes, France. Tel. : (+33) 0223238152 Fax : (+33) 0223238120

E-Mail address : aymen.assadi@ensc-rennes.fr,
} 
maximal target of $85.91 \%$ and a desirability of $\mathrm{d}=1.0,[\mathrm{MB}]=75 \mathrm{mg} / \mathrm{L},\left[\mathrm{Zn}^{2+}\right]=45 \mathrm{mg} / \mathrm{L}$, $[\mathrm{NaCl}]=0.125 \mathrm{M}$ and $\mathrm{Q}=500 \mathrm{~mL} / \mathrm{min}$. Moreover, results showed that zinc had a good affinity to cellulose material and contributed on enhancing the photocatalytic activity in terms of degradation. Mineralization of the dye was assessed for the optimal conditions using the TOC method. Moreover, special attention was also paid to better understand the effect of inorganic pollutant, scavenging effects of different molecules such as EDTA, isopropyl alcohol and $\mathrm{CCl}_{4}$ were examined and discussed.

Keywords: Heterogeneous photocatalysis, falling film photoreactor, simultaneous pollutants, Design of experiment, semi-pilot scale.

\section{Introduction}

During the last decades, industrial activities powered by an evolved rate of civilization, resulted in a noticeable increase in goods production and natural resources consumption. This quick tendency caused, however, the raise of international concerns about ecological issues and environmental sustainability. In fact, a considerable change in the composition of atmosphere, soil and water was noted, due to the increasing amount of pollutants discharged in natural media. Water contamination by industrial by-products is commonly observed in open seas and water streams, where factories discharge their effluents without a sufficient treatment (Wiedmer et al., 2016). High pollutants concentration outrun the self-purifying aspect of natural water bodies and caused the degradation of the soil and water quality. Industrial effluents loaded with dyes are a very common type of water pollution. According to recent studies, the worldwide annual production of dyes was estimated by 70000 tons, from which 100 tons are thrown in nature without a prior treatment (Gürses et al., 2016). Such behavior could affect badly on the wild and human life since most of the dye could be toxic and carcinogenic. Furthermore, due to their complex and rigid organic composition, dye molecules are not efficiently bio-degradable and could prevent sunlight penetration through 
water streams layers, which boosts the accentuation of eutrophication phenomenon (Athanasekou et al., 2015).

Methylene blue (MB) is one of the most commonly used dyes in industrial processes, thanks to its high solubility that could reach $50 \mathrm{~g} / \mathrm{L}$ and its high tainting capacity. Although $\mathrm{MB}$ is not considered to be poisonous chemical, it was recorded that exposure to this dye could lead to serious skin injuries and common cases of mental illusions and methemoglobinemia (Azzaz et al., 2017). In addition to that, its admission orally could cause multiple digestive and cardiovascular complications.

In this context, many studies were performed to treat industrial effluents loaded with dyes, namely coagulation-flocculation ( $\mathrm{Li}$ et al., 2016), membrane separation (Zhao et al., 2015) and biological degradation (Bilal et al., 2017). Despite their high efficiency for dye removal from aqueous solution, these techniques produce important amounts of sludge and by-products that necessitate additional treatment procedures (Gürses et al., 2016). Advanced Oxidation Processes (AOPs) techniques emerged as a very interesting wastewater treatment process. Heterogeneous photocatalysis figures as a promising AOP measure since it gives start to a quick chemical reaction that occurs on the surface of a given semi-conductor, and leads to the creation of highly oxidizing ${ }^{\circ} \mathrm{OH}$ and ${ }^{\circ} \mathrm{HO}_{2}$ radicals. This technique was the subject of many studies, citing that heterogeneous photocatalysis delivers high purifying efficiency of organic material from aqueous solution. These researches, however, did not sufficiently consider the adaptation of this interesting method to the real industrial effluents. In fact, the majority of these studies were performed under static conditions (batch reactors) to explore the pollution removal (Baghriche et al., 2016; Bailón-García et al., 2017). Although this investigation is essential to understand the importance of the physical-chemical parameters that could affect the degradation mechanisms, the extrapolation of the experimental data to industrial scale is generally difficult (Aghdasinia et al., 2016). 
Furthermore, real wastewater are generally loaded with both organic and inorganic material, and are characterized with high salinity due to the excessive use of metals and salts during the tainting processes (Kyzas et al., 2015; Liu et al., 2016). In this context, zinc appears as one of the most used metals in actual industrial activities since it is widely applied on the fixation of dyes on polyester fiber or in the molds galvanization process (Kyzas et al., 2015). The majority of studies treating the aqueous pollution with zinc were oriented to the elimination of heavy metals through adsorption on organic and inorganic material or by simple precipitation in form of a hydroxide salt (Miller et al., 2013). In parallel, some investigations suggested that metals could have some photocatalytic properties, as they could be involved in the generation on free oxidizing radicals under specific experimental conditions (Kyung et al., 2005).

The main objectives of this study are: i) To determine the optimal experimental conditions for the degradation of methylene blue in aqueous solution in presence of ions and at high salinity, ii) To have a better understanding on the effect of parameters variation on the organic pollution removal and finally iii) to investigate on the possible reactions that occurred during the photocatalytic reaction.

\section{Materials and methods}

\subsection{Chemicals and methods}

In the present study, titanium dioxide applied onto cellulosic paper was used as a fixed catalyst throughout all the experiments. The preparation methodology of the catalyst was cited by Assadi et al. (2015) as follows: a dry mixture of $50 \mathrm{wt} \%$ colloidal silica and $50 \mathrm{wt} \%$ titanium dioxide nanoparticles $\left(\mathrm{TiO}_{2}, \mathrm{PC} 500\right.$ Anatase, Purity $>99 \%$, specific surface area 350 - $400 \mathrm{~m}^{2} / \mathrm{g}$ ) (Millennium inorganic chemicals, Thann, France) is suspended in pure water (Assadi et al., 2014). The deposition of $16 \mathrm{~g} / \mathrm{m}^{2}$ of dry $\mathrm{TiO}_{2}$ on cellulosic support was ensured by preparing a solution composed of $40 \%$ dry powder and $60 \%$ pure water. An industrial- 
sized press was employed to impregnate the fibers with the suspension. The obtained paper was dried in an oven at $105^{\circ} \mathrm{C}$ and then stored in rolls for subsequent use.

The used cationic dye, methylene blue (MB) $\left(\mathrm{C}_{16} \mathrm{H}_{18} \mathrm{ClN}_{3} \mathrm{~S}, \mathrm{MW}=319.852 \mathrm{~g} / \mathrm{mol}\right.$, purity $>99.5 \%$ ) was acquired from Riedel-deHaën chemicals (Seelze, Germany). The desired MB solutions were prepared by diluting a stock solution at a concentration of $1 \mathrm{~g} / \mathrm{L}$ with ultrapure water (at a given resistivity of $18.2 \mathrm{M} \Omega . \mathrm{cm}$ ). The MB removal from aqueous solutions was determined using two methods: i) by measuring the progress in time of the measured absorbance at $664 \mathrm{~nm}$ by using a Varian Cary UV-Vis spectrophotometer (Palo Alto, USA)) and ii) by determining the organic content in the solution by the mean of a Shimadzu A-200 total organic carbon (TOC) analyzer (Tokyo, Japan). Inorganic pollutants effect was followed by using aqueous zinc nitrates $\left(\mathrm{Zn}\left(\mathrm{NO}_{3}\right)_{2} \cdot 6 \mathrm{H}_{2} \mathrm{O}, \mathrm{MW}=297.47 \mathrm{~g} / \mathrm{mol}\right)$ purchased from Panreac quimica (Barcelone, Spain). A stock solution of $1 \mathrm{~g} / \mathrm{L}$ was prepared and dilutions were performed to obtain the desired concentrations. Zinc variation was followed using an AA-200 Shimazu atomic absorption unit (Tokyo, Japan). Sodium chloride $(\mathrm{NaCl}, \mathrm{MW}=$ $58.44 \mathrm{~g} / \mathrm{mol}$ ) was obtained from Acros organics (Pittsburgh, USA) and was used to modify the ionic strength in the aqueous solution in order to simulate a real industrial wastewater. Carbon tetrachloride $\left(\mathrm{CCl}_{4}, \mathrm{MW}=153.81 \mathrm{~g} / \mathrm{mol}\right)$, ethylenediaminetetraacetic acid (EDTA, $\mathrm{C}_{10} \mathrm{H}_{16} \mathrm{~N}_{2} \mathrm{O}_{8}, \mathrm{MW}=292.24 \mathrm{~g} / \mathrm{mol}$ ) and isopropyl alcohol (2-propanol, $\mathrm{C}_{3} \mathrm{H}_{8} \mathrm{O}, \mathrm{MW}=60.10$ g/L) were acquired from Sigma Aldrich (St. Louis, Missouri, USA) and were used to investigate the degradation mechanism. Identical concentrations of $0.1 \mathrm{M}$ of each chemical were prepared by dissolving the required volume or mass in ultra-pure water.

\subsection{Reactor set-up}

The used semi-pilot, presented in Fig. 1.a and 1.b consists of a five steps stainless steel falling film photoreactor. Photocatalyst was applied on the steps and the counter-steps $(6 \mathrm{~cm}$ 
in width and $25 \mathrm{~cm}$ in length each) to cover the totality of the reactor which corresponds to a total used $\mathrm{TiO}_{2}$ dose of $4 \mathrm{~g}$. Therefore, the covered surface of the using the $\mathrm{TiO}_{2}$ doped cellulosic paper was about $0.18 \mathrm{~m}^{2}$. The reactor weir was filled with glass balls to ensure a uniform flow of water on the surface of the catalyst. Afterwards, a $2 \mathrm{~L}$ aqueous solution of appropriate $\mathrm{MB}$, zinc and $\mathrm{NaCl}$ concentrations was injected upwards from a solution tank, using a peristaltic electro pump (Cole-Parmer, Illinois, USA) and under continuous stirring. Overflow at the reactor weir will cause the flow of aqueous solution on the reactor steps. Three UV-lamps delivering a spectral emission ranged between 350 and $390 \mathrm{~nm}$ each (Phillips, Amsterdam, Nederland) were fixed on a lid that is used to cover up the reactor. Adsorption of dye on the cellulosic media surface was followed in black (Absence of UVradiation) until its total saturation, to ensure that the decrease in $\mathrm{MB}$ absorbance is only due to a photocatalytic degradation. In all experiments, water film is considered to be of an equal thickness in both vertical and horizontal flowing. Small volumes that did not exceed $5 \%$ of the total circulated aqueous solution volume were extracted from a basin under the reactor to do the appropriate analysis. Appropriate dilutions were performed to fit the calibration curves.

\subsection{Catalysis characterization}

A high-resolution microscopy analysis was performed using a JSM 7100F scanning electron microscope (Jeol, Tokyo, Japan) to study the morphological modifications that occurred on the catalyst surface before and after catalytic activity. The scanning electron microscope (SEM) system was coupled with an energy-dispersive X-ray spectroscope (EDS) (Oxford Instruments, Oxfordshire, UK) in order to determine its atomic composition. Later, same samples were analyzed by FTIR spectroscopy (Perkin Elmer, Massachusetts, USA) to identify the functional groups involved during the adsorption/degradation of MB molecules.

\subsection{Experimental design}


A central composite rotatable design (CCRD) was used to determine the optimal conditions for the removal of methylene blue from aqueous solution in falling film photoreactor at high conductivity values and in presence of heavy metal. As demonstrated by many studies, this approach takes in consideration the interaction between the chosen parameters, all with minimizing the number of experiments and the used reagents (Aghdasinia et al., 2016; Azzaz et al., 2016). In the present study, a design of four parameters at five cubic levels was set using the Response Surface Methodology approach (RSM). These parameters were named as follows: initial $\mathrm{MB}$ concentration $\left(\mathrm{X}_{1}\right)$, initial zinc concentration $\left(\mathrm{X}_{2}\right)$, initial $\mathrm{NaCl}$ concentration $\left(\mathrm{X}_{3}\right)$, and water flow rate $\left(\mathrm{X}_{4}\right)$. A total set of 31 experiments were performed subdivided in sixteen cubic points, eight axial points and seven points at the center. The model was set to follow the MB discoloration percentage after 180 minutes of UVradiation, according to the experimental matrix presented in table 1 . The mathematical approaches and calculations used for the choice of low, high and axial points are commonly described in the literature (Azzaz et al., 2016; Ghaedi et al., 2015). Minitab 17 software (Pennsylvania, USA) was used to analyze experimental data.

It is interesting for industrial upscaling to maximize the dye degradation percentage. For this purpose, the response optimization was elaborated using the desirability function method (DF). It allows us to determine the optimal values for the studied parameters to reach the maximal, minimal or a target response (Ghaedi et al., 2015). The DF value is between 0 and 1 related to a minimum and a maximum desirability, respectively. According to Derringer and Suich (Derringer and Suich, 1980), the desirability functions $\left(\mathrm{df}_{\mathrm{i}}\right)$ are resulting from the analysis of experimental responses of the fixed parameters and they are given by the following equations:

$d f_{i}=\left(\frac{U-\alpha}{\beta-\alpha}\right)^{w_{i}}, \quad \alpha \leq U \leq \beta$ 
$d f_{i}=1, \quad U>\beta$

$d f_{i}=1, \quad U<\alpha$

where $U$ is the upper acceptable value to the desired response, $\alpha$ and $\beta$ are the lowest and the highest values, respectively, for a given response $\mathrm{I}, \mathrm{w}_{\mathrm{i}}$ is the weight (In this study, all the $\mathrm{w}_{\mathrm{i}}$ terms were set equal to 1). All desirability functions are then combined into an overall DF function by calculating their geometric means as follows:

$D F=\left[d f_{1}^{v 1} \times d f_{2}^{v 2} \ldots \times d f_{n}^{v n}\right]^{1 / n}, \quad 0 \leq v_{i} \leq 1(i=1,2, \ldots, n)$

$\sum_{i=1}^{n} v_{i}=1$

where $\mathrm{df}_{\mathrm{i}}$ are the desirability functions for responses $\mathrm{U}_{\mathrm{i}}(\mathrm{i}=1,2 \ldots n)$, and $\mathrm{v}_{\mathrm{i}}$ represent the importance of the responses. By applying the previous equations, we were able to determine the desirability function for the present model based on the recorded highest values (Bezerra et al., 2008; Kalavathy M. et al., 2009). All statistical calculations were elaborated for a confidence level of $95 \%(p<0.05)$.

It is worth mentioning that all the experiments were performed in three independent parallel sample solutions and the mean value was retained for the statistical analysis. Moreover, tests showed that the standard deviation of the results was estimated by $\pm 3 \%$.

\section{Results and discussion}

\subsection{Catalyst characterization}

To have a better understanding on the physico-chemical properties of the catalyst before and after photocatalysis reaction, characterization was elaborated using multiple apparatus.

SEM imaging showed that the photocatalyst presented an important porosity, which allows both organic and mineral pollutants to be adsorbed on its surface (Fig. 2. a). Furthermore, the equal distribution of $\mathrm{TiO}_{2}$ powder on the surface of the cellulosic paper will 
permit an homogeneous liberation of free oxidizing radicals under UV-radiation. After aqueous solution inlet, SEM images presented a homogeneous morphology with equal partition of white spheres proving the adsorption of $\mathrm{MB}$ molecules and zinc ions on the catalyst (Fig. 2.b). Moreover, a crystallographic structure that corresponds to the salt deposit on the surface. These findings were confirmed by the EDS analysis (Fig. 3.a and 3.b). In fact, spectroscopy analysis on the initial catalyst emphasized the adsorption of $\mathrm{TiO}_{2}$ onto cellulosic paper. After effluent inlet, a decrease in the oxygen peak was noted with the appearance of two new ones that correspond to $\mathrm{Zn}^{2+}$ and $\mathrm{Na}^{+}$ions, which proves their adsorption on the functional sites of the cellulosic paper (Fig. 3.b).

Fourier transformation infrared (FTIR) spectroscopy was performed on the photocatalyst before and after effluent introduction, and the results presented in the Fig. 4 emphasized on the heterogeneous aspect of the catalyst surface, and highlighted the existence of a multitude of functional groups namely hydroxyl, carbonyl, phenolic and carboxylic groups (Fig.4.a). Peaks observed at $3305 \mathrm{~cm}^{-1}$ represents the spectrum bands of $v(\mathrm{O}-\mathrm{H})$ groups, indicators of polysaccharides and cellulose molecules (Azzaz et al., 2015), $v(\mathrm{C}-\mathrm{H})$ vibrations were recorded at $2902 \mathrm{~cm}^{-1}$ indicating the presence of methylene $\left(-\mathrm{CH}_{2}\right)$ and methyl $\left(-\mathrm{CH}_{3}\right)$ groups. $v(\mathrm{C}=\mathrm{O})$ carbonyl stretch were found at $1735 \mathrm{~cm}^{-1}$, characterizing ester and aldehyde groups (Azzaz et al., 2015). Carboxylic $v\left(\mathrm{COO}^{-}\right)$stretching related to primary and secondary alcohols, aliphatic and ether groups were found at $1641 \mathrm{~cm}^{-1}$. Ester stretching $v(\mathrm{C}-\mathrm{O})$ were observed at the spectrum range between 1365 and $1217 \mathrm{~cm}^{-1}$. The same catalyst was analyzed after injection of the effluent in the reactor, and the results showed a transmittance decrease in the catalyst spectrum, which could be attributed to the neutralization of the functional groups, and their involvement in the fixation of dye molecules and zinc ions. Furthermore, several peaks deviations were recorded for the used catalyst functional groups. In fact, $v(\mathrm{O}-\mathrm{H})$ peak deviation from 3309 to $3305 \mathrm{~cm}^{-1}$ was noticed, confirming the involvement of hydroxyl 
groups in the retention of $\mathrm{MB}$ and zinc. Same behavior was found for $\mathrm{v}(\mathrm{C}-\mathrm{H})$ groups, with a deviation from 2904 to $2899 \mathrm{~cm}^{-1}$, and for carbonyl groups from 1734 to $1735 \mathrm{~cm}^{-1}$. Ether groups are also susceptible of reacting with organic/inorganic pollutants with the vibration between 1207 and $1203 \mathrm{~cm}^{-1}$.

\subsection{Effect of the studied parameters on the MB discoloration percentage}

Experimental results revealed that the maximal methylene blue conversion rate after 180 min of UV-radiation was about $79.27 \%$ corresponding to an initial dye concentration of 75 $\mathrm{mg} / \mathrm{L}$, initial zinc concentration of $60 \mathrm{mg} / \mathrm{L}, \mathrm{NaCl}$ concentration of $0.250 \mathrm{M}$ and a flowrate of $0.7 \mathrm{~L} / \mathrm{min}$. On the other hand, the minimal conversion rate was $16.02 \%$ for an experiment corresponding to $100 \mathrm{mg} / \mathrm{L}$ of $\mathrm{MB}, 90 \mathrm{mg} / \mathrm{L}$ of $\mathrm{Zn}^{2+}, 0.375 \mathrm{M}$ of $\mathrm{NaCl}$ and a flowrate of 1 $\mathrm{L} / \mathrm{min}$. The conversion percentages in vs. the combined effect of two parameters in function are presented in the Fig. 5.

The parameters verification showed that the initial salt concentration could be considered as the most influencing term as its corresponding coefficient presents the highest absolute value amongst the studied parameters according to the equation Eq.S2. Furthermore, the increase in $\mathrm{NaCl}$ concentration decreased the $\mathrm{MB}$ discoloration percentage as it was varied simultaneously with other parameters (Fig. 5). This observation is due to the fact that sodium ions enter in competition with $\mathrm{MB}$ on the occupation of functional groups on the surface of the catalyst, which prevents dye molecules to trigger the photocatalytic process and reduces its degradation rate.

Water flowrate parameter was found also to be statistically substantial and had an important influence on the other factors. In fact, results show that the increase in flow velocity could enhance the adsorption of dye molecules and metallic ions, which rises the photocatalytic activity on the surface of the catalyst. In fact, the increase in solution flowrate 
increases the dye and metallic ions diffusion rate from the liquid to the solid phase (Azzaz et al., 2017). After reaching an optimal MB discoloration percentage for flowrate value around $500 \mathrm{~mL} / \mathrm{min}$, dye degradation efficiency decreased gradually until reaching an estimated minimum of about $16.02 \%$ that corresponds to a flowrate of $1500 \mathrm{~mL} / \mathrm{min}$ (Fig. 5). This finding could be attributed to the screening effect generated by the increasing solution volume, which prevents the sufficient penetration of light radiations to the catalyst surface (Erdemoglu et al., 2008).

When studying the effect of initial dye concentration, it could be supposed that the overall influence of MB is positive when it is added to other studied parameters. Dye concentration usually decreases the photocatalytic activity when increased, due to the screening effect caused by the molecules (Moussa et al., 2016). However, in the present study, the co-presence of $\mathrm{MB}$ with mineral pollutant seemed to enhance the discoloration percentage until a certain optimum (Fig. 5). It is worth mentioning that the interaction between MB molecules and other parameters was statistically insignificant (Fig. 5). Similar results were found by Cho et al. (Cho and Zoh, 2007) when investigating the degradation of reactive red 120 using $\mathrm{TiO}_{2}$ catalyst in continuous stirring mode.

Similar outcome was remarked when studying the impact caused by the variation of initial zinc concentration. In fact, the increase of metal concentration in the solution seemed to enhance the photocatalytic activity, until reaching an optimum value between 80 and 100 $\mathrm{mg} / \mathrm{L}$ that corresponds to an optimal dye concentration between 75 and $125 \mathrm{mg} / \mathrm{L}$ (Fig. 5). This result suggests that $\mathrm{Zn}^{2+}$ ions were involved in a homogeneous degradation process characterized with the generation of free oxidizing radicals that enhanced the MB removal rate. This results were highlighted by Kyung et al. (Kyung et al., 2005) when investigating the degradation of dyes in presence of some heavy metals in batch mode. 


\subsection{MB degradation optimization using desirability function}

The optimal conditions for the degradation of MB in falling bed photoreactor in presence of heavy metal was elaborated using the desirability function. Experimental data and secondorder polynomial equation (See Supplementary file, Eq. S2) related to the discoloration percentage after 180 min of UV-radiation were used to determine the ideal parameters points using desirability function optimizer (DF). In general, the desirability response varies from a minimum; e.g. $\mathrm{d}=0$ which corresponds to the undesirability limit, and $\mathrm{d}=1.0$ that corresponds to the highest desirability limit (Azzaz et al., 2016). In the present case, the simulator was ran in order to maximize the response for the highest possible discoloration percentage. Statistical sweet spot was determined as follows: For a maximal target of $85.91 \%$ and a desirability of $\mathrm{d}=1.0,[\mathrm{MB}]_{\mathrm{i}}=75 \mathrm{mg} / \mathrm{L},\left[\mathrm{Zn}^{2+}\right]_{\mathrm{i}}=45 \mathrm{mg} / \mathrm{L},[\mathrm{NaCl}]_{\mathrm{i}}=0.125 \mathrm{M}$ and $\mathrm{Q}=$ $500 \mathrm{~mL} / \mathrm{min}$. In order to ensure the feasibility and the validity of the model, an experiment was assessed at the latter conditions, and showed that MB conversion rate after 180 of UVradiation was estimated by $88.96 \%$ (Figure - S5). It could be concluded that the elaborated design of experiment is valid since it presents an error value that is inferior to $5 \%(p<0.05)$.

\subsection{Degradation investigation and zinc adsorption}

Zinc concentration during the catalysis process was assessed at the previously cited optimal conditions and results were presented in Fig. 6. At the beginning of the experiment and before UV-radiation, zinc adsorption on the catalyst reached $71.65 \%$, the measured zinc concentration at the samples after $60 \mathrm{~min}$ of saturation dropped from 47.01 to $13.32 \mathrm{mg} / \mathrm{L}$. This finding confirms that cellulosic paper have a good affinity towards metals thanks to the good partition of hydroxyl functional groups. However, under light radiation, metal concentration seemed to increase progressively in the solution and went from 13.32 to 25.75 mg/L (Fig. 6). This outcome could be attributed to the tendency of the catalyst to reach a 
thermodynamic equilibrium between the solution and the surface of the cellulosic paper. In fact, as dye degradation rate seemed to decrease after $180 \mathrm{~min}$, zinc ions were desorbed from hydroxyl groups and substituted by MB molecules (Fig. 6). Furthermore, it could also be remarked that the total mineralization of the organic content was reached after 700 min of UV radiation.

\subsection{Effect of $\bullet \mathrm{OH}$ radicals, hole scavengers and mechanisms investigation}

As widely cited in previous studies, heterogeneous photodegradation reaction resulting from the excitation of titania's interface, is mainly driven by the oxidizing effect of the generated free radicals such as ${ }^{\circ} \mathrm{OH}$ and/or an entity from the ${ }^{\circ} \mathrm{HO}_{2} /{ }^{\circ} \mathrm{O}_{2}{ }^{-}$redox couple. To have a better understanding on the generation mechanisms of the oxidizing species and their source, MB degradation experiments were conducted at the optimal conditions with the addition of chemicals that are known for their electron/hole scavenging properties. Alcohols (e.g. Isopropanol, $0.1 \mathrm{M}$ ) are commonly used to evaluate the oxidation capacity of the catalyst under photo radiation. Although their adsorption in aqueous solution onto Titania or cellulosic media is insignificant, the degradation rate of aliphatic alcohols in presence of oxidizing hydroxyl groups is faster than any other complex molecule. On the other hand, water molecules could be also involved in the generation of ${ }^{\circ} \mathrm{HO}_{2} /{ }^{\circ} \mathrm{O}_{2}{ }^{-}$oxidizing species. Since the experiments were conducted at a natural $\mathrm{pH}(\mathrm{pH}=6.0)$, a diluted solution of $0.1 \mathrm{M}$ of $\mathrm{CCl}_{4}$ were introduced in the reactor to quantify the amount of the generated ${ }^{\circ} \mathrm{HO}_{2}$ radicals. It is worth mentioning that many studies indicated that ${ }^{\circ} \mathrm{OH}$ radicals generated from the excitation of $\mathrm{TiO}_{2}$ are usually found adsorbed on the media, as their lifetime does not exceed some nanoseconds ( $\mathrm{Li}$ et al., 2012). In addition to that, according to the design of experiment studies, metallic ions could have an effect on the degradation of MB molecules by contributing in the generation of highly oxidizing radicals. In fact, some researches pointed out that zinc could generate ${ }^{\circ} \mathrm{OH}$ free radicals in aqueous solution (Devi et al., 2010). To 
highlight the difference, a $0.1 \mathrm{M}$ EDTA solution was introduced in the reactor in order to occupy the $\mathrm{TiO}_{2}$ functional sites, leading to a lack in the ${ }^{\circ} \mathrm{OH}_{\text {ads }}$ radicals production on the surface, leaving only ${ }^{\circ} \mathrm{OH}_{\text {free }}$ radicals to be present in the bulk solution. As it could be remarked from the Fig. 7 , ${ }^{\circ} \mathrm{OH}$ radicals are the main $\mathrm{MB}$ oxidizing specie since the estimated degradation efficiency did not exceed $13 \%$ from the initial dye concentration when introducing the isopropanol in the solution after $300 \mathrm{~min}$ of light radiation. This finding was confirmed by scavenging the ${ }^{\cdot} \mathrm{HO}_{2}$ as their absence did not deliberately affect the degradation rate, and decreased after 300 min of UV-radiation from 92.29 to $83.60 \%$ for experiments without scavenger and in presence of $\mathrm{CCl}_{4}$, respectively (Fig. 7). The effect of the ${ }^{\circ} \mathrm{OH}$ radicals issuing from the catalytic activity of zinc ions was illustrated by a noticeable decrease in the degradation percentage with about $61.15 \%$ when using EDTA after 300 min of radiation, compared to the experiment without scavenger.

Based on these observations, the overall mechanism could be summarized through the following formulas:

i) A degradation pathway through adsorbed ${ }^{\circ} \mathrm{OH}$ radicals:

$\mathrm{TiO}_{2}+h v \rightarrow \mathrm{TiO}_{2}\left(e^{-}{ }_{C B}+h^{+}{ }_{V B}\right)$

$\mathrm{TiO}_{2}\left(h^{+}{ }_{V B}\right)+\mathrm{H}_{2} \mathrm{O} \rightarrow \mathrm{TiO}_{2}+\bullet \mathrm{OH}_{a d s}+\mathrm{H}^{+}$

- $\mathrm{OH}_{\text {ads }}+M B_{a d s} \rightarrow$ Degradation products

ii) A degradation pathway through free ${ }^{\circ} \mathrm{OH}$ radicals:

$\mathrm{H}_{2} \mathrm{O} \rightarrow \mathrm{H}^{+}+\mathrm{OH}^{-}$

$\mathrm{Zn}^{2+}+\mathrm{TiO}_{2}\left(h^{+}{ }_{V B}\right) \rightarrow \mathrm{Zn}^{3+}+\mathrm{TiO}_{2}$

$\mathrm{Zn}^{3+}+\mathrm{OH}^{-} \rightarrow \mathrm{Zn}^{2+}+\bullet \mathrm{OH}_{\text {free }}$ 
- $O H_{\text {free }}+M B_{\text {ads }} \rightarrow$ Degradation products

$\mathrm{Zn}^{3+}+\mathrm{TiO}_{2}\left(e^{-}{ }_{C B}\right) \rightarrow \mathrm{Zn}^{2+}+\mathrm{TiO}_{2}$

\subsection{Catalyst reusability}

The multiple use of the catalyst is considered by industrial of a crucial importance in order to abate the wastewater management expenses and to limit the amount of by-products resulting from the effluents treatments. For this purpose, a succession of 5 degradation cycles (3 hours radiation period each) using the same catalyst was elaborated at optimal conditions $\left([\mathrm{MB}]_{\mathrm{i}}=75 \mathrm{mg} / \mathrm{L},\left[\mathrm{Zn}^{2+}\right]_{\mathrm{i}}=45 \mathrm{mg} / \mathrm{L},[\mathrm{NaCl}]_{\mathrm{i}}=0.125 \mathrm{M}, \mathrm{Q}=500 \mathrm{~mL} / \mathrm{min}\right)$. Results presented in the Fig. 8 show that the degradation percentage slightly decreased from $89 \%$ to $81 \%$ between first and fifth cycle, respectively. This decrease is mainly caused by the successive saturation of hydroxyl groups on the surface of the cellulosic paper by dye molecules, zinc and sodium ions. This finding suggests that the catalyst could be efficiently reused for the treatment of industrial textile wastewater.

\section{Conclusion}

This study investigates the discoloration of a synthetized textile effluent at a laboratory scale using a semi-pilot photocatalytic reactor. The presence of a simultaneous organic and mineral pollutants in the solution was followed according to a central composite rotatable design of experiment. Results suggest that the presence of metal ions at a certain aqueous concentration could enhance the photocatalytic degradation rate of methylene blue molecules. Statistic study confirmed the presence of an experimental optimum for a maximum MB degradation and the mathematical was successfully validated and presented an error of about 3\%. Degradation mechanism was assessed through experiments using radicals scavengers namely chloroform, EDTA and isopropanol. Related observations showed that degradation 
process is mainly driven by the generation of free radicals issued from the photoexcitation of zinc ions present on the surface of the catalyst. This finding could be attributed to the involvement of zinc ions in the generation of free ${ }^{\circ} \mathrm{OH}$ radicals in presence of a UV radiation. The multiple use of the titania-doped cellulosic paper in the treatment of textile effluents was also assessed at optimal conditions and results confirmed that the catalyst could be repeatedly used for multiple treatment cycles.

\section{Acknowledgments}

This research work has been carried out in the framework of a Tunisian national project. Financial support of this work by the Tunisian Ministry of Higher Education and Scientific Research is gratefully acknowledged.

\section{References}

Aghdasinia, H., Bagheri, R., Vahid, B., Khataee, A., 2016. Central composite design optimization of pilot plant fluidized-bed heterogeneous Fenton process for degradation of an azo dye. Environ. Technol. (United Kingdom) 37. doi:10.1080/09593330.2016.1159734

Assadi, A.A., Bouzaza, A., Lemasle, M., Wolbert, D., 2015. Acceleration of Trimethylamine Removal Process Under Synergistic Effect of Photocatalytic Oxidation and Surface Discharge Plasma Reactor 93, 1239-1246. doi:10.1002/cjce.22211

Assadi A.A., Bouzaza A, Wolbert D., Petit P., 2014.Isovaleraldehyde elimination by UV/TiO2 photocatalysis: comparative study of the process at different reactors configurations and scales. Environmental Science and Pollution Research 21(19):1117888.doi: $\quad 10.1007 / \mathrm{s} 11356-014-2603-7$

Athanasekou, C.P., Moustakas, N.G., Morales-Torres, S., Pastrana-Martínez, L.M., 
Figueiredo, J.L., Faria, J.L., Silva, A.M.T., Dona-Rodriguez, J.M., Romanos, G.E., Falaras, P., 2015. Ceramic photocatalytic membranes for water filtration under UV and visible light. Appl. Catal. B Environ. 178, 12-19. doi:10.1016/j.apcatb.2014.11.021

Azzaz, A.A., Jellali, S., Akrout, H., Assadi, A.A., Bousselmi, L., 2016. Optimization of a cationic dye removal by a chemically modified agriculture by-product using response surface methodology: biomasses characterization and adsorption properties. Environ. Sci. Pollut. Res. 1-16. doi:10.1007/s11356-016-7698-6

Azzaz, A.A., Jellali, S., Assadi, A.A., Bousselmi, L., 2015. Chemical treatment of orange tree sawdust for a cationic dye enhancement removal from aqueous solutions: kinetic, equilibrium and thermodynamic studies. Desalin. Water Treat. 3994, 1-13. doi:10.1080/19443994.2015.1103313

Azzaz, A.A., Jellali, S., Souissi, R., Ergaieg, K., 2017. Alkaline-treated sawdust as an effective material for cationic dye removal from textile effluents under dynamic conditions: breakthrough curve prediction and mechanism exploration. Environ. Sci. Pollut. Res. 1-17. doi:10.1007/s11356-017-9388-4

Baghriche, O., Rtimi, S., Pulgarin, C., Kiwi, J., 2016. Polystyrene CuO/Cu2O uniform films inducing MB-degradation under sunlight. Catal. Today. doi:10.1016/j.cattod.2016.10.018

Bailón-García, E., Elmouwahidi, A., Álvarez, M.A., Carrasco-Marín, F., Pérez-Cadenas, A.F., Francisco J., M.-H., 2017. New carbon xerogel-TiO2 composites with high performance as visible-light photocatalysts for dye mineralization. Appl. Catal. B Environ. 201, 2940. doi:10.1016/j.apcatb.2016.08.015

Bezerra, M.A., Santelli, R.E., Oliveira, E.P., Villar, L.S., Escaleira, L.A., 2008. Response surface methodology (RSM) as a tool for optimization in analytical chemistry. Talanta 
76, 965-977. doi:10.1016/j.talanta.2008.05.019

Bilal, M., Asgher, M., Parra-Saldivar, R., Hu, H., Wang, W., Zhang, X., Iqbal, H.M.N., 2017. Immobilized ligninolytic enzymes: An innovative and environmental responsive technology to tackle dye-based industrial pollutants - A review. Sci. Total Environ. 576, 646-659. doi:10.1016/j.scitotenv.2016.10.137

Cho, I.H., Zoh, K.D., 2007. Photocatalytic degradation of azo dye (Reactive Red 120) in TiO2/UV system: Optimization and modeling using a response surface methodology (RSM) based on the central composite design. Dye. Pigment. 75, 533-543. doi:10.1016/j.dyepig.2006.06.041

Derringer, G., Suich, R., 1980. Simultaneous Optimization of Several Response Variables. J. Qual. Technol. doi:10.1017/CBO9781107415324.004

Devi, L.G., Murthy, B.N., Kumar, S.G., 2010. Photocatalytic activity of TiO2 doped with $\mathrm{Zn} 2+$ and V5+ transition metal ions: Influence of crystallite size and dopant electronic configuration on photocatalytic activity. Mater. Sci. Eng. B Solid-State Mater. Adv. Technol. 166, 1-6. doi:10.1016/j.mseb.2009.09.008

Erdemoglu, S., Aksu, S.K., Sayılkan, F., Izgi, B., Asilturk, M., Say1lkan, H., Frimmel, F., Gucer, S., 2008. Photocatalytic degradation of Congo Red by hydrothermally synthesized nanocrystalline TiO 2 and identification of degradation products by LC MS 155, 469-476. doi:10.1016/j.jhazmat.2007.11.087

Ghaedi, M., Mazaheri, H., Khodadoust, S., Hajati, S., Purkait, M.K., 2015. Application of central composite design for simultaneous removal of methylene blue and $\mathrm{Pb} 2+$ ions by walnut wood activated carbon. Spectrochim. Acta - Part A Mol. Biomol. Spectrosc. 135, 479-490. doi:10.1016/j.saa.2014.06.138 
Gürses, A., Açıkyıldız, M., Güneş, K., Sadi Gürses, M., 2016. Dyes and Pigments. doi:10.1007/978-3-319-33892-7

Kalavathy M., H., Regupathi, I., Pillai, M.G., Miranda, L.R., 2009. Modelling, analysis and optimization of adsorption parameters for $\mathrm{H} 3 \mathrm{PO} 4$ activated rubber wood sawdust using response surface methodology (RSM). Colloids Surfaces B Biointerfaces 70, 35-45. doi:10.1016/j.colsurfb.2008.12.007

Kyung, H., Lee, J., Choi, W., 2005. Simultaneous and synergistic conversion of dyes and heavy metal ions in aqueous $\mathrm{TiO} 2$ suspensions under visible-light illumination. Environ. Sci. Technol. 39, 2376-2382. doi:10.1021/es0492788

Kyzas, G.Z., Siafaka, P.I., Pavlidou, E.G., Chrissafis, K.J., Bikiaris, D.N., 2015. Synthesis and adsorption application of succinyl-grafted chitosan for the simultaneous removal of zinc and cationic dye from binary hazardous mixtures. Chem. Eng. J. 259, 438-448. doi:10.1016/j.cej.2014.08.019

Li, H., Liu, S., Zhao, J., Feng, N., 2016. Removal of reactive dyes from wastewater assisted with kaolin clay by magnesium hydroxide coagulation process. Colloids Surfaces A Physicochem. Eng. Asp. 494, 222-227. doi:10.1016/j.colsurfa.2016.01.048

Li, P., Zhao, G., Zhao, K., Gao, J., Wu, T., 2012. An efficient and energy saving approach to photocatalytic degradation of opaque high-chroma methylene blue wastewater by electrocatalytic pre-oxidation. Dye. Pigment. 92, 923-928. doi:10.1016/j.dyepig.2011.06.009

Liu, W., Sun, W., Borthwick, A.G.L., Wang, T., Li, F., Guan, Y., 2016. Simultaneous removal of $\mathrm{Cr}(\mathrm{VI})$ and 4-chlorophenol through photocatalysis by a novel anatase/titanate nanosheet composite: Synergetic promotion effect and autosynchronous doping. J. 
Hazard. Mater. 317, 385-393. doi:10.1016/j.jhazmat.2016.06.002

Miller, A., Wildeman, T., Figueroa, L., 2013. Zinc and nickel removal in limestone based treatment of acid mine drainage: The relative role of adsorption and co-precipitation. Appl. Geochemistry 37, 57-63. doi:10.1016/j.apgeochem.2013.07.001

Moussa, H., Girot, E., Mozet, K., Alem, H., Medjahdi, G., Schneider, R., 2016. ZnO rods/reduced graphene oxide composites prepared via a solvothermal reaction for efficient sunlight-driven photocatalysis. Appl. Catal. B Environ. 185, 11-21. doi:10.1016/j.apcatb.2015.12.007

Wiedmer, D., Sagstuen, E., Welch, K., Haugen, H.J., Tiainen, H., 2016. Oxidative power of aqueous non-irradiated $\mathrm{TiO} 2-\mathrm{H} 2 \mathrm{O} 2$ suspensions: Methylene blue degradation and the role of reactive oxygen species. Appl. Catal. B Environ. 198, 9-15. doi:10.1016/j.apcatb.2016.05.036

Zhao, R., Wang, Y., Li, X., Sun, B., Wang, C., 2015. Synthesis of ??-cyclodextrin-based electrospun nanofiber membranes for highly efficient adsorption and separation of methylene blue. ACS Appl. Mater. Interfaces 7, 26649-26657. doi:10.1021/acsami.5b08403 


\section{Figures caption}

Fig. 1: Experimental apparatus

Fig. 2: SEM imaging of the catalyst (a) before and (b) after effluent treatment

Fig. 3: EDS analysis of the catalyst (a) before and (b) after effluent treatment

Fig. 4: FTIR spectroscopy of the catalyst (a) before and (b) after effluent treatment

Fig. 5: $3 D$ response surface for the $2^{4}$ central composite designs $\left(X_{1}\right.$ : $M B$ concentration, $X_{2}$ : Zinc concentration, $\mathrm{X}_{3}$ : $\mathrm{NaCl}$ concentration and $\mathrm{X}_{4}$ : Water flowrate)

Fig. 6: (a) Image of the discoloration kinetic of the effluent after $300 \mathrm{~min}$ of UV-radiation and (b) the total organic carbon (TOC) and zinc concentration variations after $800 \mathrm{~min}$ of UVradiation

Fig. 7: Effect of isopropanol, $\mathrm{CCl}_{4}$ and EDTA $(0.1 \mathrm{M})$ on the efficiency of discoloration of methylene blue $(75 \mathrm{mg} / \mathrm{L})$ in falling film photoreactor

Fig. 8: Catalyst discoloration percentage after five consecutive uses of the same photocatalyst at the optimal conditions 
Fig.1.a

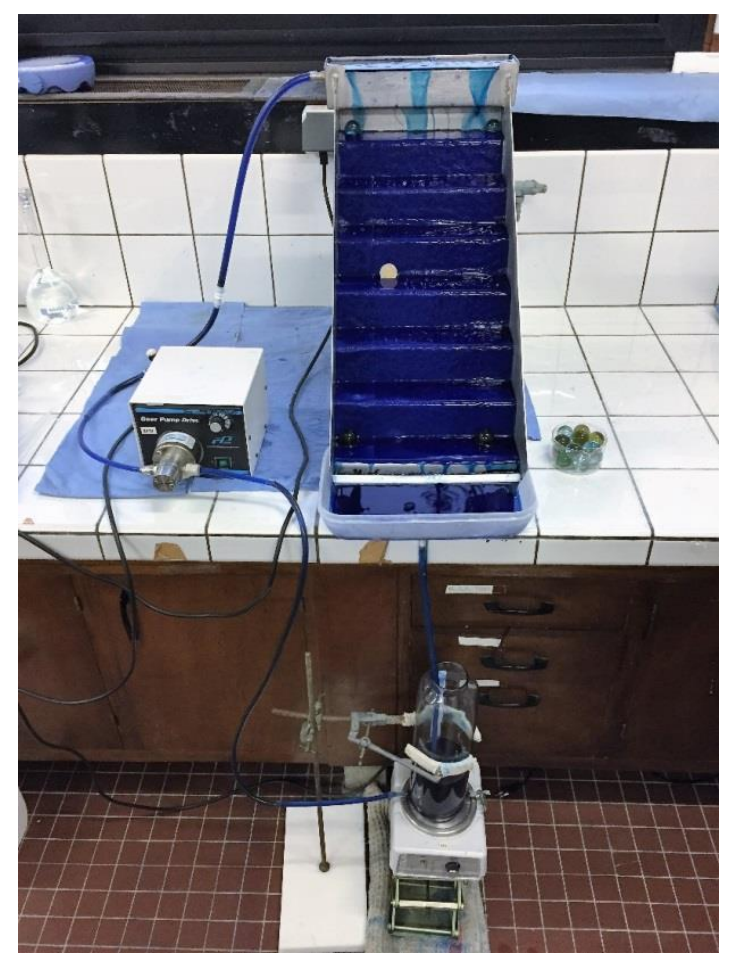

Fig. 1.b

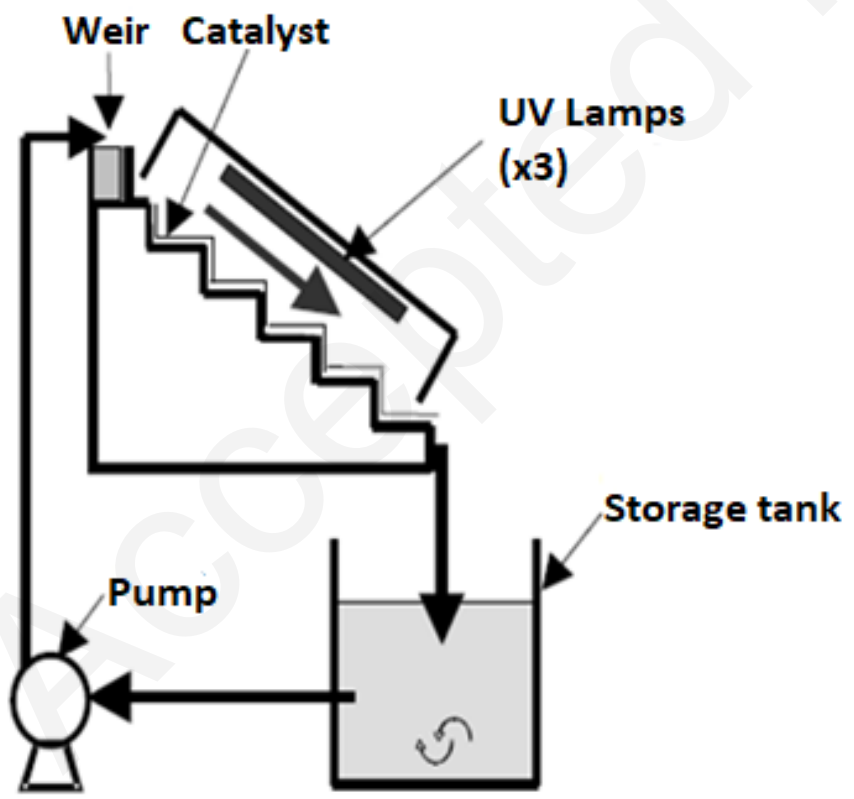


Fig.2




Fig. 3
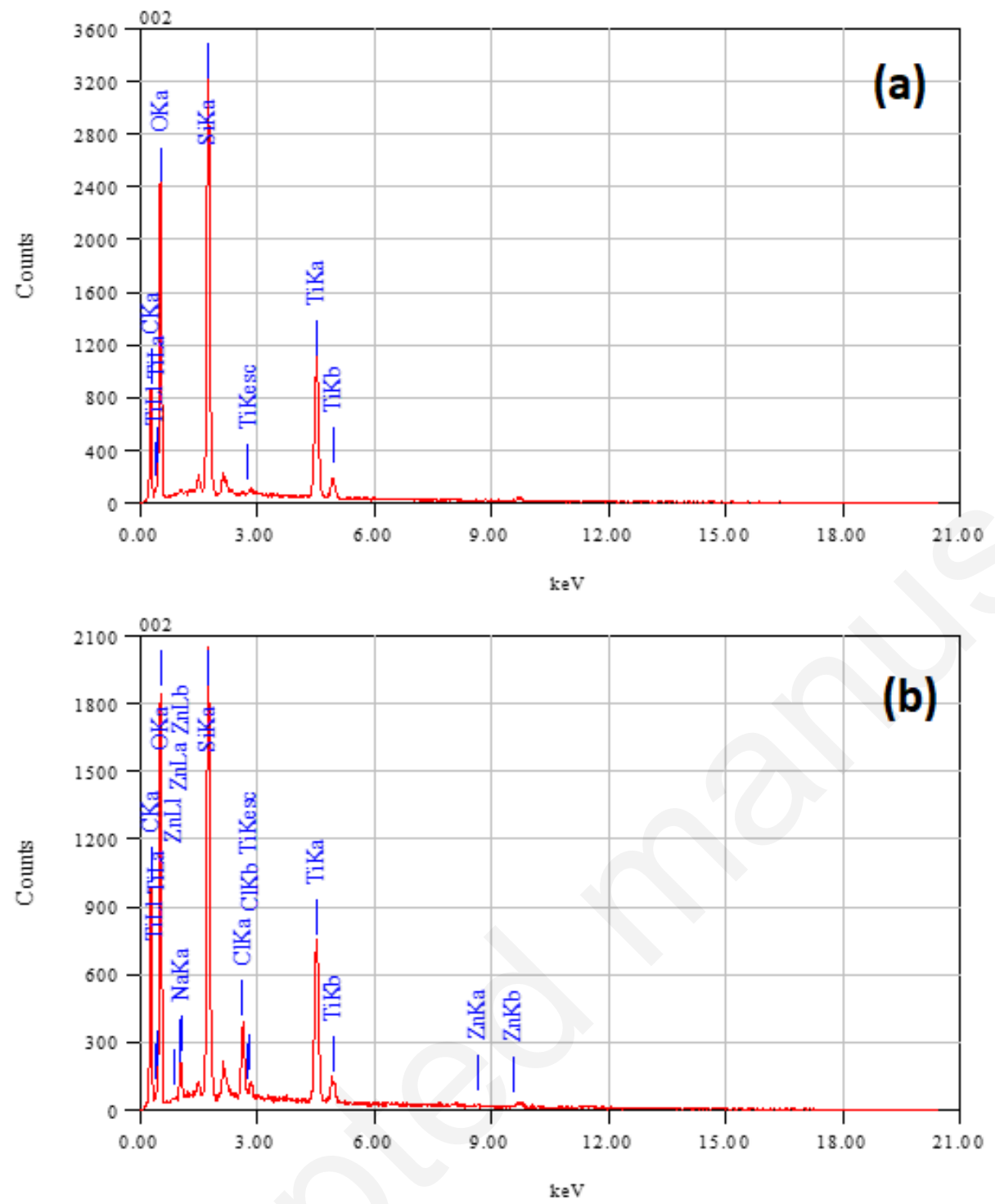
Fig. 4

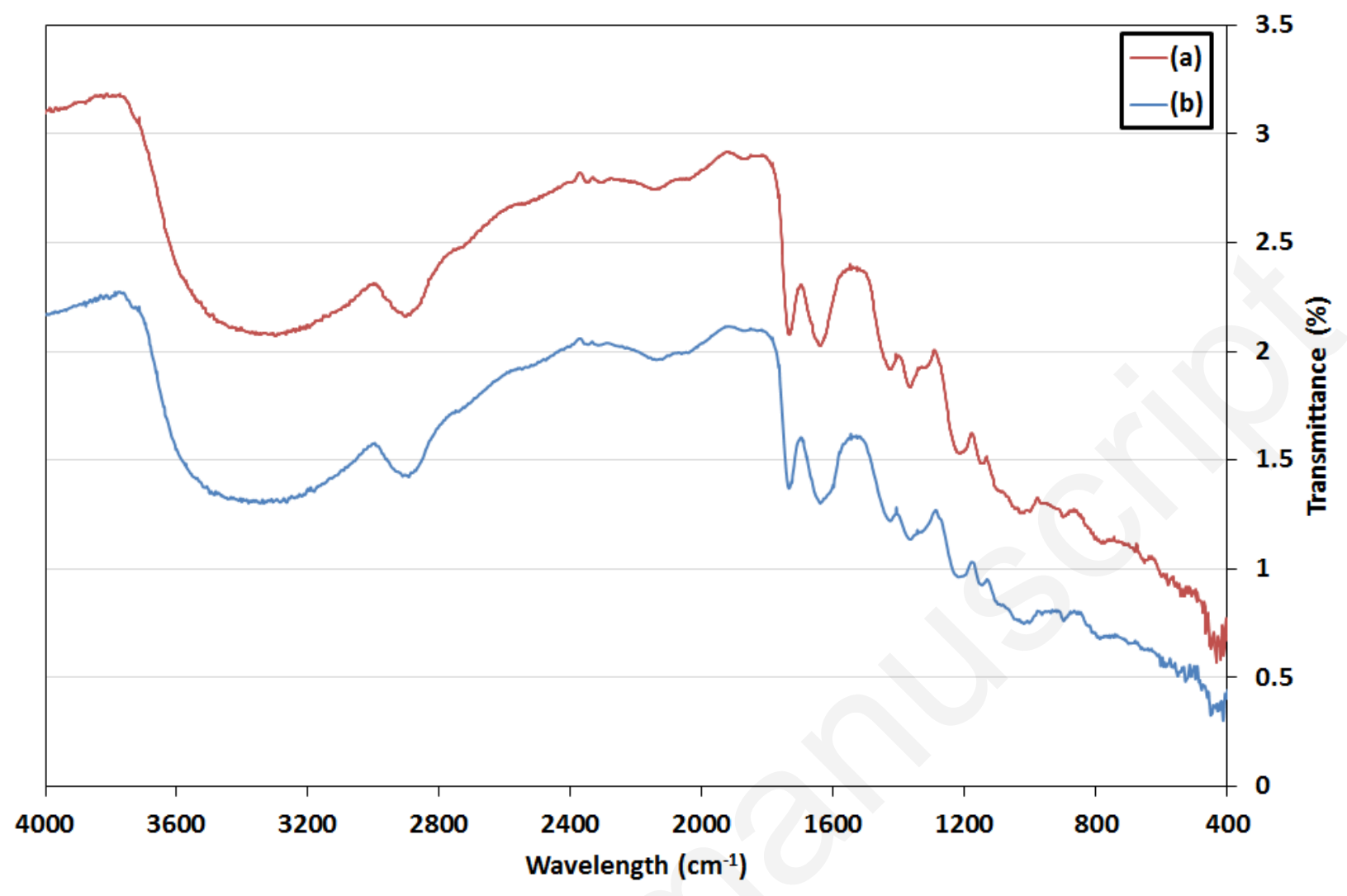


Fig. 5

Fig. 5.a

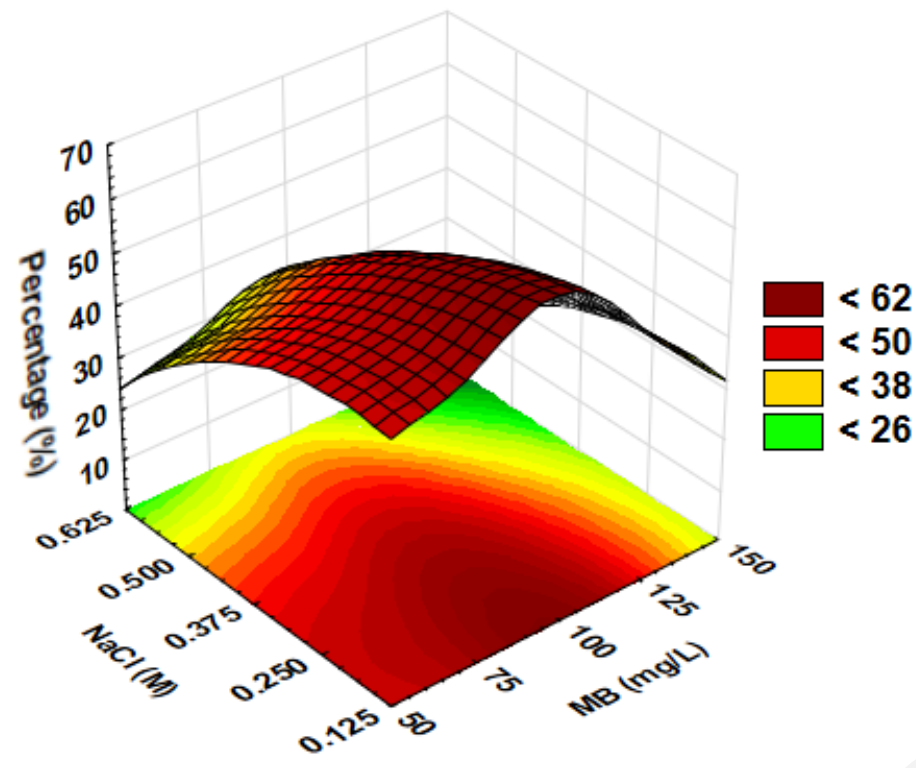

Fig. 5.b

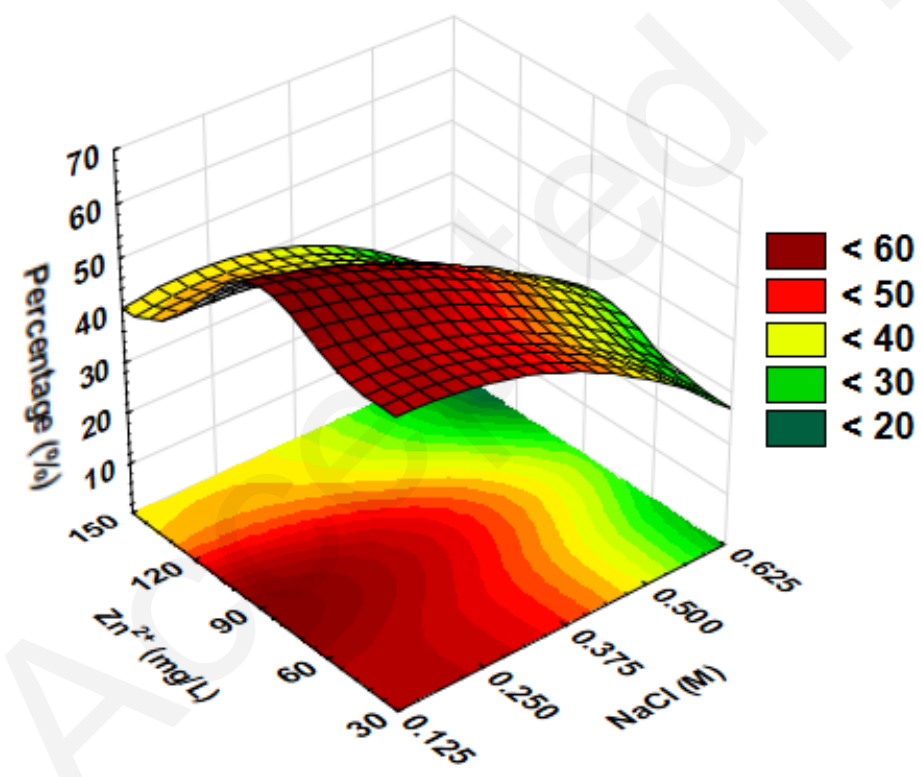


Fig. 5.c

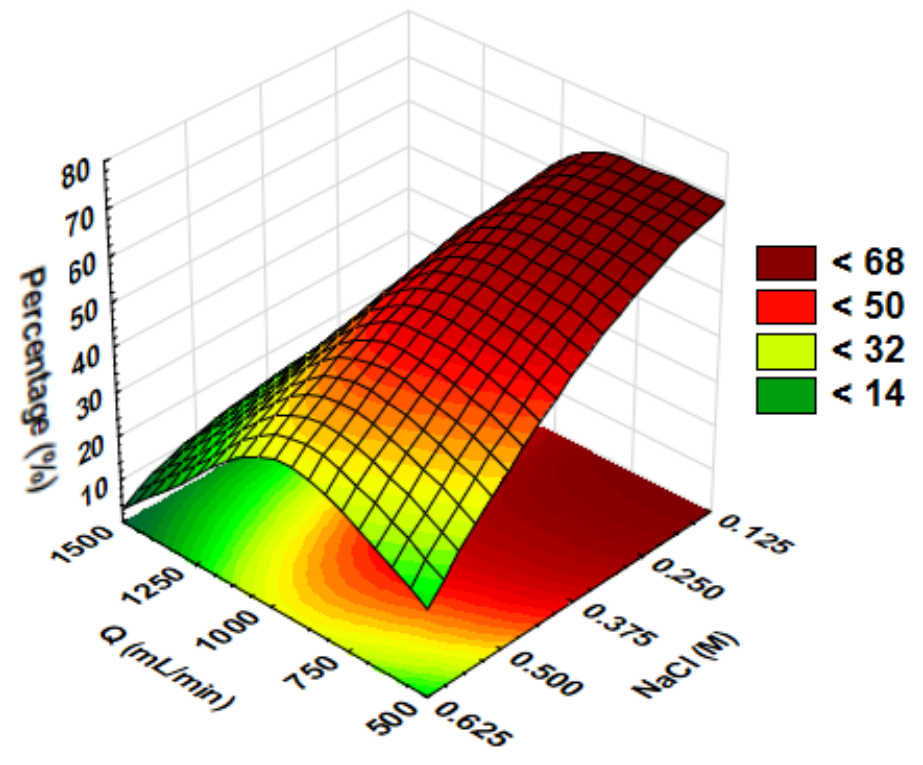

Fig. 5.d

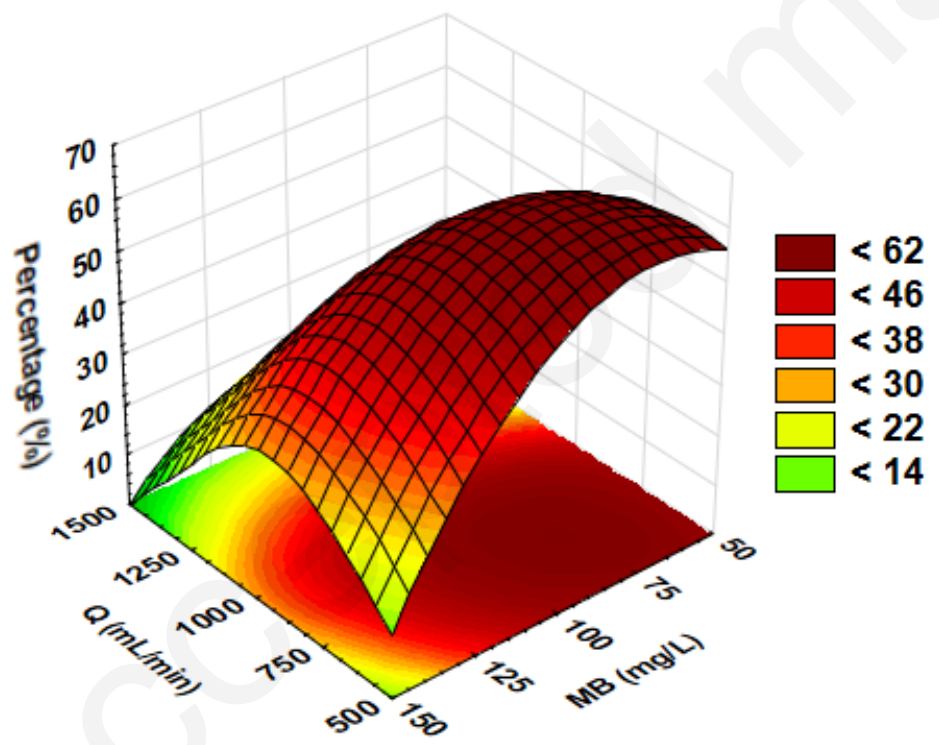


Fig. 5.e



Fig. 5.f




Fig. 6

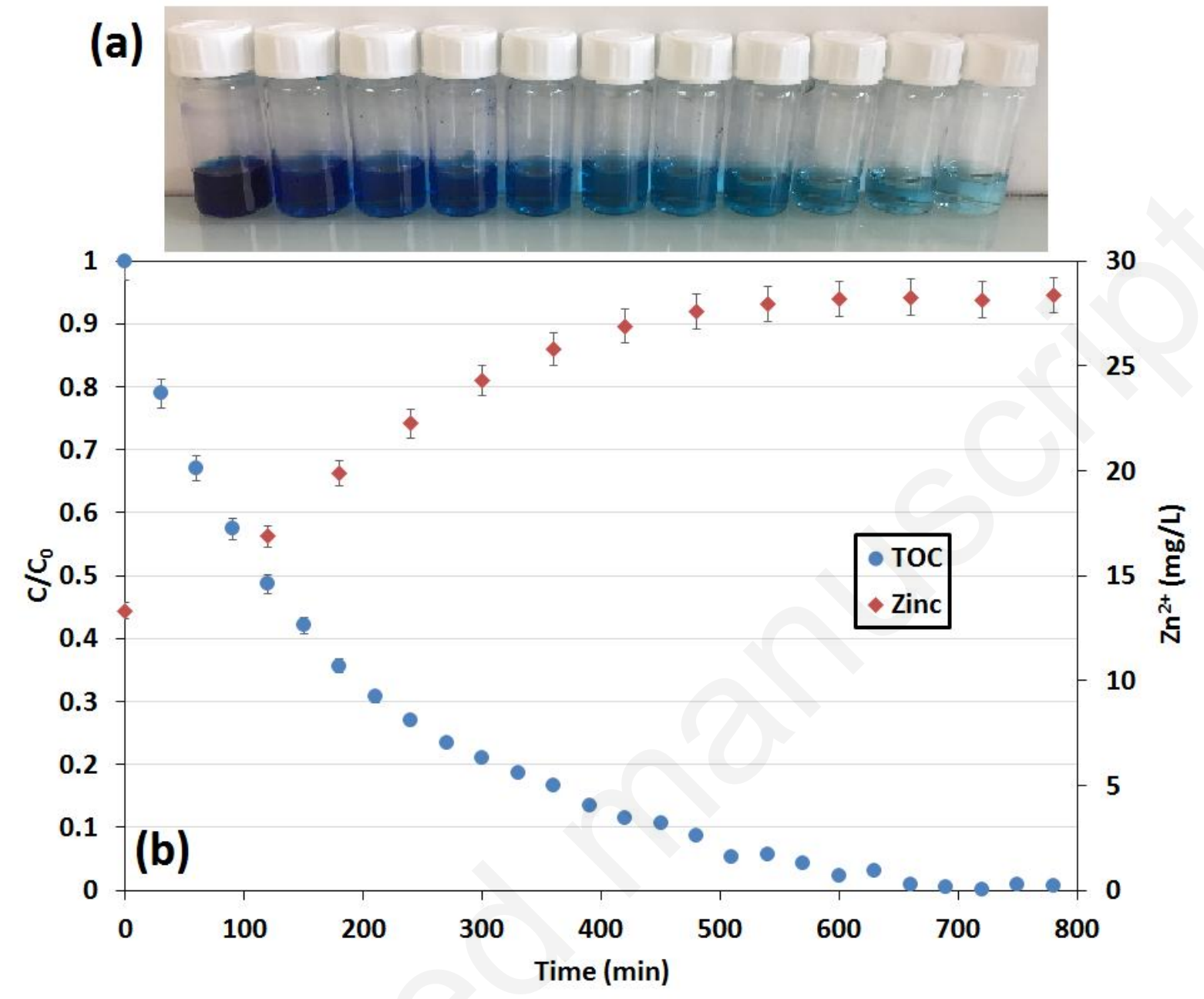


Fig.7

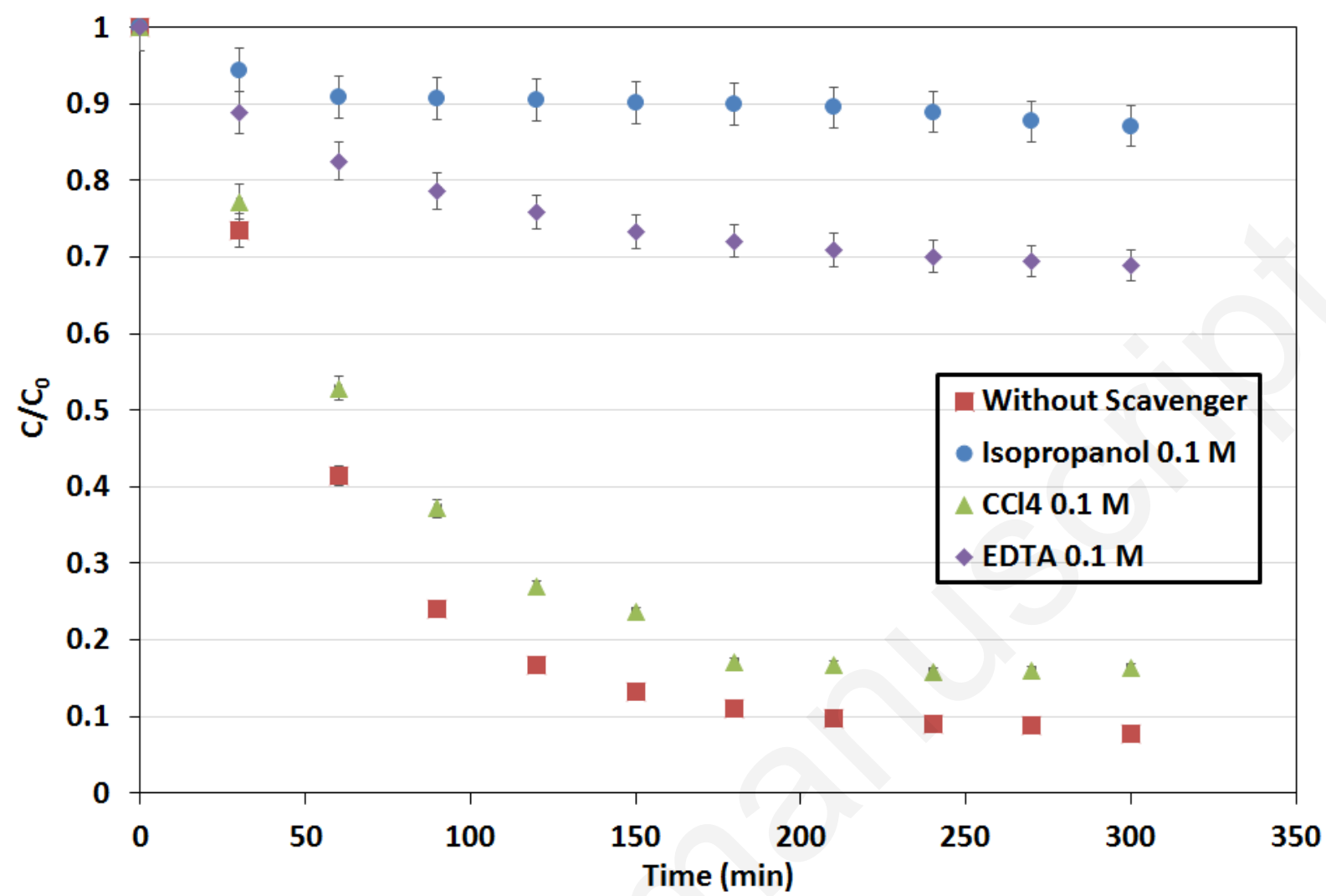


Fig. 8

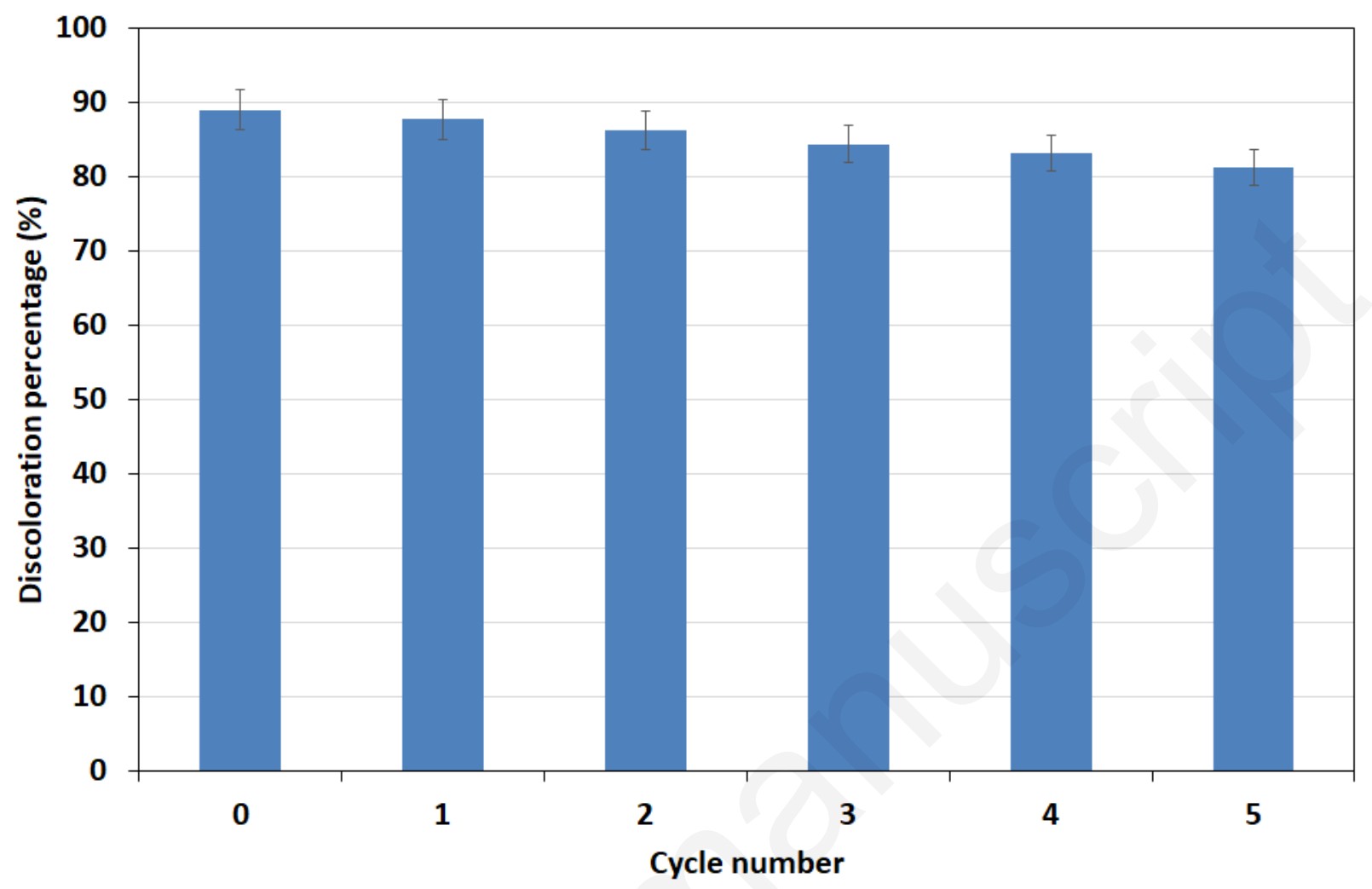


Table 1: Level of the factors used for the study of MB in falling film photoreactor in presence of an inorganic pollution using the central composite design approach $\left(\mathrm{X}_{1}: \mathrm{MB}\right.$ concentration $(\mathrm{mg} / \mathrm{L}), \mathrm{X}_{2}$ : Zinc concentration $(\mathrm{g} / \mathrm{L}), \mathrm{X}_{3}: \mathrm{NaCl}$ concentration (Mole), $\mathrm{X}_{4}$ : Solution flowrate (mL/min), $\pm \alpha$ : axial points)

\begin{tabular}{cccccc}
\hline & $(-\alpha=-2)$ & Low (-1) & Central (0) & High $(+1)$ & $(+\alpha=2)$ \\
\hline $\mathrm{X}_{1}$ & 50 & 75 & 100 & 125 & 150 \\
\hline $\mathrm{X}_{2}$ & 30 & 60 & 90 & 120 & 150 \\
\hline $\mathrm{X}_{3}$ & 0.125 & 0.25 & 0.375 & 0.5 & 0.625 \\
\hline $\mathrm{X}_{4}$ & 500 & 750 & 1000 & 1250 & 1500 \\
\hline
\end{tabular}

